https://www.journal-imab-bg.org

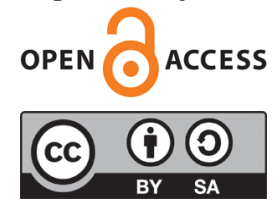

Case report

\title{
GLUTEN-FREE DIET - SOCIAL BURDEN AND IMPACT ON THE QUALITY OF LIFE IN ADULT PATIENTS - CASES FROM PRACTICE
}

\author{
Lili Grudeva \\ Clinic of Gastroenterology, Hepatology and Nutrition, Department of Internal \\ Diseases, Medical University of Varna, Bulgaria.
}

\begin{abstract}
The last decade has brought a change in the social perception of gluten-sensitive enteropathy (GE), both in the minds of physicians and patients. It has turned from a rare condition into a more and more widely spread autoimmune systemic disease. The gluten-free diet (GFD) is not an "exclusive" therapy for patients anymore but rather a popular healthy choice for an increasing number of people. Gluten-free foods, hard to find 5-6 years ago and requiring skills to prepare at home, are already available in many more grocery stores, diabetic and bio food stores, restaurants and food establishments. Despite all this, the quality of life of GE sufferers is still compromised, especially for those who find it hard to adhere to GFD and patients with asymptomatic or oligosymptomatic forms of the disease at the moment of establishing the diagnosis.
\end{abstract}

Keywords: gluten-sensitive enteropathy, glutenfree diet, quality of life, social burden,

\section{BACKGROUND}

The last decade has brought a change in the social perception of gluten-sensitive enteropathy (GE), both in the minds of physicians and patients. It has turned from a rare condition into a more and more widely spread autoimmune systemic disease. The gluten-free diet (GFD) is not an "exclusive" therapy for patients anymore but rather a popular healthy choice for an increasing number of people.

\section{CASE DESCRIPTION}

The change in patients' minds and their awareness and perception of GE is a subject of constant evolution.

Our clinical experience and direct observation of patients have revealed the following factors, participating in the perceived quality of life $(\mathrm{QoL})$ :

- awareness of the disease;

- social burden;

- QoL and coping strategies.

In order to establish the current situation among GE patients a survey involving a number of our patients was conducted. We have selected some of the comments made by patients during outpatient visits as an example of the most difficult situations, in which they have found themselves, and tried to analyze their insights and concerns.

„I feel calmer if my doctor has an in-depth knowledge of my condition.“ A. G., 39 y.o.

,When I go out with friends, I feel different from them. In my small town there is no restaurant, which serves gluten-free food." S.H., 28 y.o.

"When I am at a restaurant with friends, I often consume gluten-containing foods because I don't want to appear different." A.G., 19 y.o.

„I don't want to go to my friend's birthday party because I don't want to say I can't eat cake due to being ill.“"

„I felt so poorly before the diagnosis, now I am a new person." S.P. 44 y.o.

When conducting a telephone survey with our patients we managed to identify two basic groups. One of them consists of patients in the process of diagnosing the disease, who are characterized by gradual acceptance of GE, awareness of it, its social and emotional impact, as well as thinking about the future. The other group is comprised of individuals who are successful in coping with the diet and different social situations. In the group of those who are handling the condition well, we have noticed that, compared to patients with other chronic diseases, GE patients are gradually coming to terms with the diagnosis and start believing that they are healthier because they do not consume unhealthy food.

\section{DISCUSSION}

Unfortunately, there are few medical specialists in Bulgaria treating directly the problems of GE patients. Good knowledge of the different presentations of the disease is rare among physicians. A study from 2005 shows the need of training among general practitioners (GPs) in California with only $35 \%$ of them having ever diagnosed this condition [1]. In Europe, the situation is dynamic. In France the awareness of GE is considerably low among GPs, whereas the diagnosis is well-known among gastroenterologists, nutritionists and pediatricians. Increased awareness is observed in Finland [2]. It has been proven that good collaboration between medical specialists leads to a better strategy for the decrease of the time between the occurrence of the first symptoms and the diagnosis. 
The application of new strategies, such as information campaigns, among GPs in the US and Italy has demonstrated an improvement in the awareness of GE and its diagnosis $[3,4]$. This has been confirmed by Catassi et al. [5] in a large-scale screening study showing that the GE diagnosis is only the tip of the iceberg with the majority of the cases being "under the waterline". Recently, after more than 10 years, Zingone et al.[6], showed that the incidence in the rural regions of Campania is lower than in other nearby provinces suggesting that the locals are more likely to visit their doctor only in case of severe symptoms, which makes diagnosing, especially the less characteristic forms of the disease, more difficult. This leads to the conclusion that the patients with lower socioeconomic status are less likely to seek medical help or consultation, thus they are potentially less likely to undergo GE testing. However, after establishing the diagnosis, the subsequent measures should include a consultation with a nutritionist, because the patients report higher satisfaction after receiving the needed psychological support as well. This has been confirmed by our data, too. The significance of psychological support has been reported by Sainsbury et al. [7], who have determined that psychological symptoms, as well as the adherence to GFD, are more strongly related to the decrease of QoL than the gastrointestinal symptoms.

\section{Social Burden}

GE patients are apprehensive when consuming food that has not been prepared at their homes. The lack of gluten-free foods and the low level of awareness among restaurant and food establishment employees has become a problem in the recent years despite the changing conditions. A survey among chefs in Great Britain from 2003 showed that they were less informed about GE than the general population. The authors conducted the same survey in 2013 and it showed a considerable increase in the chefs' awareness about gluten-related disorders and recognition of the gluten-free symbols [8, 9].

In the recent decades, patient support groups have played an important role in the organization of special social events for patients, their families, doctors and people working in the food industry. The lack of such in Bulgaria presents a difficulty for a large part of our patients.

Many reports show that the individual training regarding nutritional therapy and efficient understanding are key factors and play an important role in the individual psychological awareness. Target therapeutic intervention by trained specialists may improve the adherence to a GFD and increase the psychological wellbeing of GE patients. Published studies and our experience show that despite the visible positive changes with time, thereisstill the need of additional training and provision of information in regard to GE and GFD.

\section{Quality of Life and Coping Strategies}

The issue of QoL and its improvement at the university, at work, at the restaurant, and the words "glutenfree diet" often do not need further clarification, they must be understood!

A review of the literature in time shows us that QoL of GE patients before and after the diagnosis is strongly influenced by the presence or lack of gastrointestinal symptoms. QoL of GE patients before the diagnosis and after its establishing is mainly related to the difficulties characteristic of a chronic condition and the limitations defined by a GFD, its maintenance and proper nutritional conformity. Poor dietary adherence is also linked to poor QoL but it is difficult to determine what is at its core the condition of the effect of GFD.

Poor diet adherence can be caused by the difficulty in coming to terms with the condition and the limitations set by GFD. Many studies in adults show the patients' inability to socialize, as well as their feeling and inclination towards behavioral conformism leading to limitation in their way of living as a whole. The patients are afraid that their social contacts in restaurants or other gatherings are events where they can be identified as suffering from a disease by the others and this will ruin their reputation. There are controversial results about the link between dietary conformity and QoL. On the other hand, it is thought that the subsequent QoL deterioration is related to the lack of proper dietary adherence. Barrattet al. [10], report that the difficult acceptance of GFD and the stemming from this poor adherence can lead to decreased QoL.

The long-lasting symptoms before the diagnosis gastrointestinal, neurological, psychiatric, and other concomitant symptoms, are a predictor of decreased QoL.

Another problem, which might possibly be underestimated, is the presence of eating disorders, which are more frequently observed in untreated women, and depend on the presence of gastrointestinal symptoms. They are improved by GFD. In addition, Zingone et al. [11], report a decreased quality of sleep both at the time of diagnosing and when adhering to a GFD. The authors have observed a direct link between the quality of sleep and mood disorders and QoL. A very small part of the answers given by the observed group of patients mentions sleep changes.

\section{CONCLUSION}

In conclusion, in the last years, a visible increase in the awareness about this disease has been observed, both among physicians and the general public. Patients with gastrointestinal problems are still a vulnerable group in terms of the adaptation to this chronic condition, especially in the social aspect of their life. A planned intervention during diagnosis and follow-up would undoubtedly improve the process of adaptation to the condition and its limitations. We must note that, in large controlled studies to determine the effect in QoL, any interventions, such as psychological support and additional dietary consultation, are still absent.

It is possible that in the future more tests would be needed in order to establish the conditions under which patients might stray from GFD and this will help in the development of suitable and efficient strategies to aid those who need support during their treatment. 
REFERENCES:

1. Zipser RD, Farid M, Baisch D, Patel B, Patel D. Physician awareness of celiac disease. J Gen Intern Med. $2005 \mathrm{Jul} ; 20(7): 644-46$. [PubMed] [CrossRef]

2. Fuchs V, Kurppa K, Huhtala H, Collin P, Mäki M, Kaukinen K. Factors associated with long diagnostic delay in celiac disease. Scand $J$ Gastroenterol. 2014; 49(11):130410. [PubMed] [CrossRef]

3. Catassi C, Kryszak D, LouisJacques O, Duerksen DR, Hill I, Crowe SE, et al. Detection of celiac disease in primary care: A multicenter case-finding study in north america. Am J Gastroenterol. 2007; 102(7): 1454-60. [PubMed] [CrossRef]

4. Berti I, Della Vedova R, Paduano $\mathrm{R}$, Devetta $\mathrm{M}$, Caradonna $\mathrm{M}$, Villanacci V, et al. Coeliac disease in primary care: Evaluation of a casefinding strategy. Dig Liver Dis. 2006; 38(7): 461-7. [PubMed] [CrossRef]
5. Catassi C, Ratsch IM, Fabiani E, Rossini M, Bordicchia F, Candela F, et al. Coeliac disease in the year 2000: Exploring the iceberg. Lancet. 1994; 343(8891):200-3. [PubMed] [CrossRef]

6. Zingone F, West J, Auricchio R, Maria Bevilacqua R, Bile G, Borgheresi $\mathrm{P}$, et al. Incidence and distribution of coeliac disease in Campania (Italy): 2011-2013. United Eur Gastroenterol J. 2015; 3(2):1829. [ $\underline{\text { PubMed] }}$ [CrossRef]

7. Sainsbury K, Mullan B, Sharpe L. Reduced quality of life in coeliac disease is more strongly associated with depression than gastrointestinal symptoms. J Psychosom Res. 2013; 75(2):135-41. [PubMed] [CrossRef]

8. Karajeh MA, Hurlstone DP, Patel TM, Sanders DS. Chefs' knowledge of coeliac disease (compared to the public): A questionnaire survey from the united kingdom. Clin Nutr. 2005;
24(2):206-10. [PubMed] [CrossRef]

9. Aziz I, Karajeh MA, Zilkha J, Tubman E, Fowles C, Sanders DS. Change in awareness of gluten-related disorders among chefs and the general public in the uk: A 10-year follow-up study. Eur J Gastroenterol Hepatol. 2014; 26(11):1228-33. [PubMed] [CrossRef]

10. Barratt SM, Leeds JS, Sanders DS. Quality of life in coeliac disease is determined by perceived degree of difficulty adhering to a gluten-free diet, not the level of dietary adherence ultimately achieved. J Gastrointest Liver Dis. 2011; 20(3): 241-5. [PubMed]

11. Zingone F, Siniscalchi M, Capone P, Tortora R, Andreozzi P, Capone E, et al. The quality of sleep in patients with coeliac disease. Aliment Pharmacol Ther. 2010; 32(8): 1031-6. [PubMed] [CrossRef]

Please cite this article as: Grudeva L. Gluten-Free Diet - Social Burden and Impact on the Quality of Life in Adult Patients - Cases from Practice. J of IMAB. 2019 Jul-Sep;25(3):2689-2691.

DOI: https://doi.org/10.5272/jimab.2019253.2689

Received: 23/01/2019; Published online: 09/09/2019

Address for correspondence:

Lili Grudeva

Clinic of Gastroenterology, Hepatology and Nutrition St. Marina University Hospital

1, Hristo Smirnenski Blvd., 9000 Varna, Bulgaria

E-mail: grudeva63@abv.bg 